\title{
NUMERICAL ANALYSIS OF THE NEAR WELLBORE FLOW MECHANISMS CONTROLLING WELL PRODUCTIVITY
}

\author{
Bakhbergen BEKBAUOV ${ }^{* 1}$, Zemfira IMANSAKIPOVA ${ }^{2}$ \\ ${ }^{* 1,2}$ Department of Petroleum Engineering, Satbayev University, 22a Satpayev St, 050013 Almaty, \\ Kazakhstan
}

*Corresponding author: bakhbergen.bekbauov@gmail.com

Received: 25 January 2018; Accepted: 29 April 2018

This study presents three-dimensional (3D), thermal mathematical model of the simultaneous flow of two-phase immiscible fluids that can be used as a practical tool for the simulation study and analysis of adjacent to wells flow phenomena controlling productivity. Based on the model, the corresponding near wellbore $3 D$ numerical model is developed subsequently, which can be used for conducting analysis of time dependent development and dynamics of the oil-water interface (OWI) around the well producing from a bottomwater reservoir. The specialized simulation tool for analyzing near-well flow has been applied to simulate the effects of relative permeability modification $(R P M)$ (or disproportionate permeability reduction (DPR)), well completion (single or dual - with the bottom water drainage) and a barrier injected around the well bore on water coning. This study presents a mechanistic study of gel injection process, the effect of gel treatment for in-situ permeability modification on two-phase flow, and posttreatment production forecasts. Model was also applied for simulating production tests with and without artificial impermeable barrier, the effect of DWS technology on water coning performance and some combination of above processes (methods). We propose a generalized version of the LET correlation for relative permeability approximation which takes into account gel - reservoir fluid transition zone. We also propose using a new formula for approximation of Leverett J-function.

Key words: Disproportionate permeability reduction, Downhole Water Sink, Near wellbore flow, Water shut-off

\section{Introduction}

In bottom water drive oil reservoirs, the phenomenon of water coning can cause increased water production and hence shorten the life of the well. Water coning has an important effect in the abnormal sweeping of heterogeneous reservoirs. The existence of barriers, channels and other heterogeneities may aggravate the bypassing of oil. Understanding the mechanisms of water invasion and oil bypassing in bottom water reservoirs is, therefore, of capital importance since it would allow identifying potential solutions. Over the years, there have been attempts to retard water cone growth, to reduce the amount of water produced and increase water-free oil production, reducing oil bypassing.

One viable technique of water shut-off confirmed by numerous field successes is the use of relative permeability modifiers without zone isolation. Particular attention is paid to the importance of 
the phenomena that high-molecular weight water-soluble polymers or weak gels adsorbed in reservoir rocks can reduce selectively the relative permeability to water more than to oil, increase water irreducible saturation, and the capillary pressure.

Another method that has been tried by the industry to control water coning is injection of gels or polymers (mechanical isolation) around the well bore. These gels create an artificial impermeable barrier around the well, which does not allow flow of water across it. It is thought that such man made barriers can prevent water coning in a vertical oil well.

The DWS technology has demonstrated to be an effective method in controlling and delaying water coning in bottom-water systems. However, the reservoir and operational conditions that would result in maximized recovery using the technology for such systems are not entirely understood [1].

Direct injection of polymer or gels in the production wells was shown to enable the reduction of the water cut. If the drawdown on the treated well can be increased, then, in addition to the reduction in water production, the treatment can induce an increase in oil production [2]. Several researchers have studied the mechanisms involved in the action of polymer or gels (Schneider and Owens [3], Liang et al. [4]). They all found that polymer or gels are able to reduce selectively the relative permeability to water with respect to the relative permeability to oil.

Wojtanowicz, Shirman, and Kurban (1999) studied DWS technology using numerical simulator and Hele-Shaw model [5]. They suggested that water production in the top completion with DWS should be optimized rather than minimized, as increasing water production can stimulate and accelerate the recovery process. Shirman and Wojtanowicz (2000) developed a numerical model for postbreakthrough water-cut calculations in conventional and DWS completions. They summarized the work done in DWS technology and concluded that field observations indicate after DWS recompletions production of oil increased and the water at the top completion was reduced but there was no reduction in total water-cut [6].

Siddiqi, S. S. and Wojtanowicz, A. K. used a scaled physical model and numerical simulator to determine the effect of DWS technology and artificial barrier on water coning performance [7]. Chen and Wan (1996) discussed placing emulsified polymer gel on top of the aquifer so that it can form an effective barrier to block water production [8]. They performed laboratory experiments to show that it was possible to make such an emulsion, which could be placed in between oil and water and would have enough gel strength to form a barrier. Strickland used a 2D two-phase numerical model to determine the effect of artificial barriers on water coning performance [9]. He concluded that barriers could be beneficial in two ways: 1) the cumulative water production to produce the same amount of oil is lesser; and 2) the time required to produce the same amount of oil is less than without the barrier.

In the present work the mathematical model of two-phase flow in porous media is used to describe thermal treatment of reservoir with bottom water. The thermal mathematical model based on the isothermal model of Muskat-Leverett (MLT model) [10-12]. The model takes heat effects into account via the known dependences on the viscosity, and capillary properties of the two-phase liquid (water-oil) components. System of equations describing the process also includes the contribution of gravity forces.

\section{Simulation tool for analysis of water coning control}

Numerical simulations were run in two phases: (1) simulation of polymer injection; (2) posttreatment production forecasts. Both of these processes are described by the same formal 
mathematical model, which results from incompressible two-phase flow equations formulated in terms of normalized saturation and global pressure.

\subsection{Mathematical model of gel injection process}

Mathematical model of gel injection process based on the MLT model of the two-phase immiscible fluids' flow through a porous medium (indexes $i=f, \mathrm{~g}, c$ correspond to, respectively, reservoir fluid, gel and core):

$$
\begin{gathered}
m \frac{\partial S}{\partial t}+\nabla \cdot\left(K_{0} \frac{k_{f} k_{\mathrm{g}}}{k} \frac{\partial p_{c}}{\partial S} \nabla S\right)=\nabla \cdot\left[K_{f}\left(\nabla p+\int_{S}^{1} \nabla \frac{\partial p_{c}}{\partial S} \frac{k_{\mathrm{g}}}{k} d S+\int_{S}^{1} \frac{\partial}{\partial \theta}\left(\frac{\partial p_{c}}{\partial S} \frac{k_{\mathrm{g}}}{k}\right) d S \nabla \theta\right)\right] \\
\vec{v}=K\left[\nabla p+\int_{S}^{1} \nabla \frac{\partial p_{c}}{\partial S} \frac{k_{\mathrm{g}}}{k} d S\right]+K \int_{S}^{1} \frac{\partial}{\partial \theta}\left(\frac{\partial p_{c}}{\partial S} \frac{k_{\mathrm{g}}}{k}\right) d S \nabla \theta+K_{\mathrm{g}}\left(\nabla p_{c}-\left(\rho_{\mathrm{g}}-\rho_{f}\right) \overrightarrow{\mathrm{g}}+\frac{\partial p_{c}}{\partial \theta} \nabla \theta\right) \\
\frac{\partial \theta}{\partial t}=\nabla \cdot[\lambda(x, s, \theta) \nabla \theta-\vec{v} \theta],
\end{gathered}
$$

where

$$
m=m_{o}\left(1-S_{f i}-S_{\mathrm{gr}}\right) ; \quad S=\frac{S_{f}-S_{f i}}{1-S_{f i}-S_{\mathrm{gr}}} \in[0,1] ; \quad S_{f}+S_{\mathrm{g}}=1 ; \quad \overrightarrow{\mathrm{g}}=-\nabla \mathrm{g} z ;
$$

$K_{0}$ is expressed via horizontal $k_{h}$ and vertical $k_{v}$ permeability components of symmetrical flow tensor.

$$
\begin{gathered}
k_{i}=\frac{k_{r i}}{\mu_{i}} ; \quad i=f, \mathrm{~g} . \quad k=k_{f}+k_{\mathrm{g}} ; \quad \mu_{\mathrm{g}}=\mu_{\mathrm{g} \max }+\left(\mu_{\mathrm{g} \min }-\mu_{\mathrm{g} \max }\right) \frac{\theta-\theta_{\min }}{\theta_{\max }-\theta_{\min }} \\
\mu_{f}=\text { const } ; \quad p_{\mathrm{g}}-p_{f}=p_{c}(x, S, \theta) \geq 0 ; \quad p_{c}(x, S, \theta)=\bar{p}_{c}(x, \theta) J(S) ; \\
\bar{p}_{c}=\sigma \cos \vartheta\left(\frac{m_{0}}{\left|K_{o}\right|}\right)^{1 / 2}=\gamma(\theta)\left(\frac{m_{0}}{\left|K_{0}\right|}\right)^{1 / 2} ; \quad \gamma=\gamma_{\max }+\left(\gamma_{\min }-\gamma_{\max }\right) \frac{\theta-\theta_{\min }}{\theta_{\max }-\theta_{\min }} ; \\
K_{i}=K_{0}(x) k_{i}(S)=K_{o}(x) \frac{k_{r i}(S)}{\mu_{i}}, \quad i=f, \mathrm{~g} ; \quad p=p_{f}-\int_{S}^{1} \frac{\partial p_{c}}{\partial S} \frac{k_{\mathrm{g}}}{k} d S+\rho_{f} \mathrm{gz} .
\end{gathered}
$$

Both fluids are assumed to be incompressible, i.e. $\rho_{i}=$ const, $i=f$, g.

$$
\begin{aligned}
& \int_{S}^{1} \frac{\partial}{\partial \theta}\left(\frac{\partial p_{c}}{\partial S} \frac{k_{\mathrm{g}}}{k}\right) d S=\sqrt{\frac{m_{o}}{K_{o}}} \int_{S}^{1} J^{\prime}(S)\left\{\frac{\gamma_{\min }-\gamma_{\max }}{\theta_{\max }-\theta_{\min }} \frac{k_{\mathrm{g}}}{k}-\gamma \frac{k_{f} k_{\mathrm{g}}}{\mu_{\mathrm{g}} k^{2}}\left(\frac{\mu_{\mathrm{g} \min }-\mu_{\mathrm{g} \max }}{\theta_{\max }-\theta_{\min }}\right)\right\} d S \\
& K=K_{0} k=K_{0}\left(k_{f}+k_{\mathrm{g}}\right) ; \quad \vec{v}=\vec{v}_{f}+\vec{v}_{\mathrm{g}} ; \\
& \vec{v}_{f}=K_{0} \frac{k_{f} k_{\mathrm{g}}}{k} \frac{\partial p_{c}}{\partial S} \nabla S-K_{f}\left[\nabla p-\int_{S}^{1} \nabla \frac{\partial p_{c}}{\partial S} \frac{k_{\mathrm{g}}}{k} d S-\int_{S}^{1} \frac{\partial}{\partial \theta}\left(\frac{\partial p_{c}}{\partial S} \frac{k_{\mathrm{g}}}{k}\right) d S \nabla \theta\right] \\
& \lambda(S, \theta)=\frac{\alpha_{f} \lambda_{f}}{\rho_{f} c_{p_{f}}}+\frac{\alpha_{\mathrm{g}} \lambda_{\mathrm{g}}}{\rho_{\mathrm{g}} c_{p_{\mathrm{g}}}}+\frac{\alpha_{c} \lambda_{c}}{\rho_{c} c_{c}} ; \quad \alpha_{f}=m_{0} S_{f} ; \quad \alpha_{\mathrm{g}}=m_{0}\left(1-S_{f}\right) ; \quad \alpha_{c}=1-m_{0} .
\end{aligned}
$$

\subsection{Numerical study of gel injection process}

For this study the reservoir geometry and field prototype have the properties as shown in Fig. 1 and Table 1, respectively. Eqs. (1)-(4) for simulation of gel injection process are solved using proper boundary conditions derived from the clear general statements in section 3.1. The successive overrelaxation method was used for the numerical solution of the pressure equation. A finite-difference scheme for the simulation of the time-dependent 3D equations describing the thermal two-phase flow in porous media in cylindrical coordinates is used. Figure 1 illustrates the geometrical domain, boundaries and interfaces of the model. Staggered grid in cylindrical coordinates is used in this model. 
The staggered grid allows an easier implementation of boundary conditions. We used Fortran for development of the specialized simulation tool for analyzing near-well flow. Tecplot visualization \& analysis software tool, developed by Tecplot, Inc., was used for post-processing the output data.

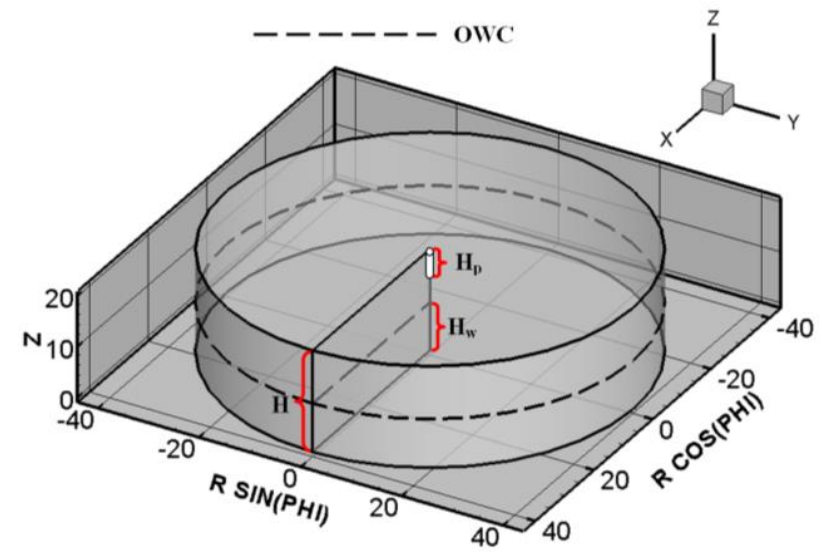

Figure 1. Computational domain and initial oil-water contact

Table 1. Reservoir geometry, rock and fluid properties considered for gel injection process

\begin{tabular}{|c|c|c|c|c|c|}
\hline Property & $\begin{array}{l}\text { Denotation } \\
\text { (Unit) }\end{array}$ & Value & Property & $\begin{array}{l}\text { Denotation } \\
\text { (Unit) }\end{array}$ & Value \\
\hline Reservoir radius & $R(\mathrm{~m})$ & 40 & Relative permeabilities & $k_{r f,} k_{r g}$ & LET \\
\hline Total thickness & $H(\mathrm{~m})$ & 20 & Porosity & $m_{0}$ (fraction) & 0.25 \\
\hline $\begin{array}{l}\text { Well perforation } \\
\text { thickness }\end{array}$ & $H_{p}(\mathrm{~m})$ & 1 & Gel injection rate & $Q_{\mathrm{g}}(\mathrm{bbl} / \mathrm{d})$ & 333.33 \\
\hline Time step size & $\Delta t(\mathrm{sec})$ & 10 & Gravity & $\mathrm{g}\left(\mathrm{m} / \sec ^{2}\right)$ & 9.8 \\
\hline $\begin{array}{l}\text { Grid blocks in radial } \\
\text { direction }\end{array}$ & $N_{r}$ & 80 & Fluid Phase Density & $\rho_{f}\left(\mathrm{~kg} / \mathrm{m}^{3}\right)$ & 850 \\
\hline $\begin{array}{l}\text { Grid blocks in } \\
\text { angular direction }\end{array}$ & $N_{\varphi}$ & 36 & Gel Density & $\rho_{\mathrm{g}}\left(\mathrm{kg} / \mathrm{m}^{3}\right)$ & 1000 \\
\hline $\begin{array}{c}\text { Grid layers in vertical } \\
\text { direction }\end{array}$ & $N_{z}$ & 40 & Rock Density & $\rho_{\mathrm{c}}\left(\mathrm{kg} / \mathrm{m}^{3}\right)$ & 4216 \\
\hline $\begin{array}{c}\text { Grid block } \\
\text { dimensions }\end{array}$ & $\Delta r, z(\mathrm{~m})$ & 0.5 & Thermal Conductivity of Fluid Phase & $\lambda_{f}(W /(\mathrm{m} \cdot K))$ & 0.644 \\
\hline $\begin{array}{l}\text { Grid block } \\
\text { dimensions }\end{array}$ & $\Delta \varphi$ (degrees) & $10^{\circ}$ & Thermal conductivity of gel & $\lambda_{\mathrm{g}}(W /(\mathrm{m} \cdot K))$ & 0.08 \\
\hline Fluid viscosity & $\mu_{f}(c p)$ & 1 & Core thermal conductivity & $\lambda_{\mathrm{c}}(W /(\mathrm{m} \cdot K))$ & 2.4 \\
\hline Gel viscosity at $\theta_{\min }$ & $\mu_{\mathrm{g} \max }(c p)$ & 20 & $\begin{array}{l}\text { Specific heat capacity coefficient of } \\
\text { fluid phase at constant pressure }\end{array}$ & $c_{p_{f}}(J /(k g \cdot K))$ & 4071 \\
\hline Gel viscosity at $\theta_{\max }$ & $\mu_{\mathrm{g} \min }(c p)$ & 10 & $\begin{array}{c}\text { Specific heat capacity coefficient of } \\
\text { gel }\end{array}$ & $c_{p_{\mathrm{g}}}(J /(k \mathrm{~g} \cdot K))$ & 2100 \\
\hline $\begin{array}{l}\text { Max.surface tension } \\
\text { at } \theta_{\min }\end{array}$ & $\sigma \mathrm{kg} / \mathrm{sec}^{2}$ & 0.03 & $\begin{array}{l}\text { Specific heat capacity coefficient of } \\
\text { core }\end{array}$ & $c_{p_{c}}(J /(k \mathrm{~g} \cdot K))$ & 920 \\
\hline $\begin{array}{l}\text { Min.surface tension } \\
\text { at } \theta_{\max }\end{array}$ & $\sigma \mathrm{kg} / \mathrm{sec}^{2}$ & 0.015 & Initial reservoir pressure & $p(P a)$ & $25 \cdot 10^{6}$ \\
\hline $\begin{array}{c}\text { Horizontal } \\
\text { permeability }\end{array}$ & $k_{\square}$ (degrees) & 2 & Initial fluid zone temperature & $\theta_{\max }(K)$ & 330 \\
\hline Vertical permeability & $k_{v}$ (degrees) & 0.6 & Initial gel zone temperature & $\theta_{\min }(K)$ & 300 \\
\hline
\end{tabular}




\subsection{Gel viscosity effect on gel penetration and distribution}

The two figures below illustrate gel viscosity effect on gel penetration and distribution at $t=$ $8 h$, where $C_{g e l}$ is the gel concentration in percent.. The Figs. 2-A and 2-B correspond to cases $\mu_{\mathrm{g}} / \mu_{f}=10$ and 0.1, respectively. The horizontal axes in Figs. 2-A and 2-B show that the cylindrical coordinate system is used to model the realistic behavior of near-well flow.

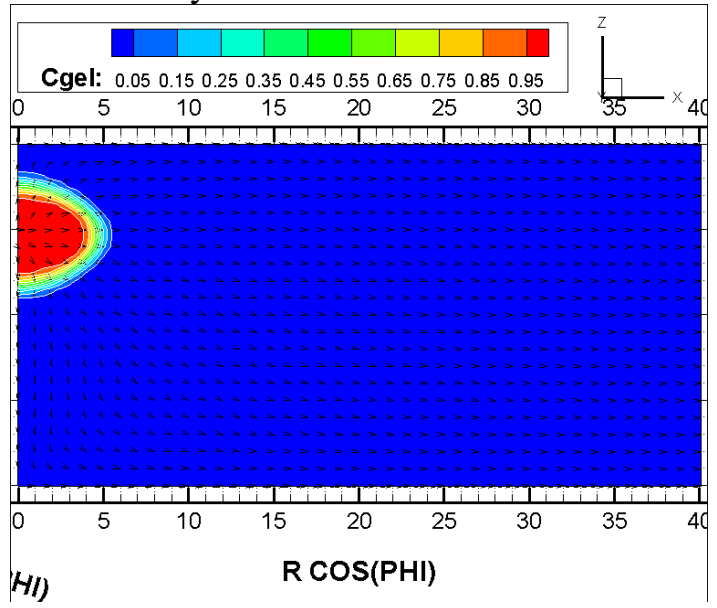

A
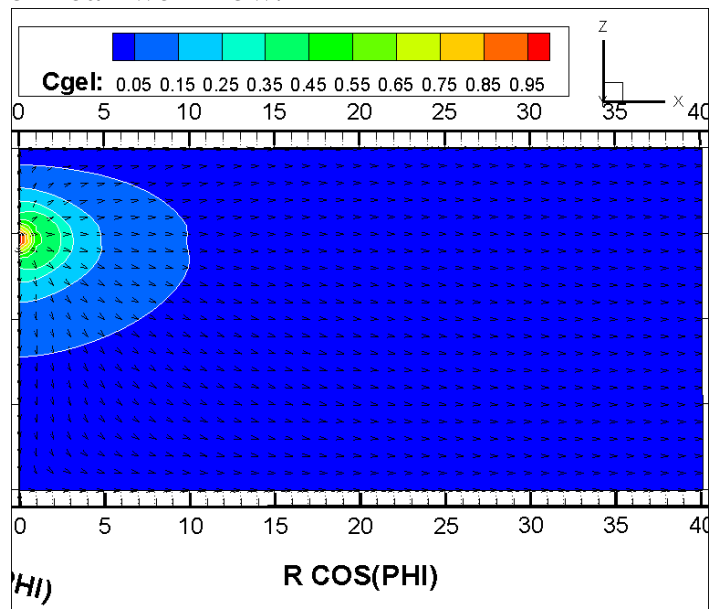

$\mathrm{B}$

Figure 2. Gel viscosity effect on gel penetration and distribution at $t=8 \mathrm{~h}$

Mechanistic study of gel injection process shows that impact of gel / reservoir fluid viscosity ratio play large role in gel distribution in a homogeneous reservoir. For a given volume of gelant injected, the gelant penetration zone and gelant - reservoir fluid transition zone are greater for a low-viscosity than for a viscous gelant (other factors being equal). Hence it is important to take into account gel reservoir fluid transition zone in the model. Advantages are a low viscosity during injection, a large adsorption and a high permeability reduction to water without the risk of well impairment by gels [13].

\subsection{New correlations for relative permeabilities and Leverett $\mathrm{J}$-function (capillary pressure)}

The LET-correlation was proposed in 2005 and has shown to be rather powerful for describing proper shape of the relative permeabilities [14]. We propose a generalized version of the LET correlation, which takes into account gel transition zone:

$$
k_{r w}=\frac{k_{r w}^{0}\left(S_{\mathrm{g}}\right) S^{L_{w}\left(S_{\mathrm{g}}\right)}}{S^{L_{w}\left(S_{\mathrm{g}}\right)}+E_{w}\left(S_{\mathrm{g}}\right) \cdot(1-S)^{T_{w}\left(S_{\mathrm{g}}\right)}} ; \quad k_{r o}=\frac{k_{r o}^{0}\left(S_{\mathrm{g}}\right) \cdot(1-S)^{L_{o}\left(S_{\mathrm{g}}\right)}}{(1-S)^{L_{o}\left(S_{\mathrm{g}}\right)}+E_{0}\left(S_{\mathrm{g}}\right) \cdot S^{T_{o}\left(S_{\mathrm{g}}\right)}} .
$$

The normalized water saturation used in the formulas is

$$
S=\frac{S_{w}-S_{w i}\left(S_{\mathrm{g}}\right)}{1-S_{w i}\left(S_{\mathrm{g}}\right)-S_{\mathrm{or}}\left(S_{\mathrm{g}}\right)} .
$$

The $k_{\text {ro }}^{0}$ coefficient was introduced into the formula because in reality end point relative permeability of oil differs from one. All the parameters in the correlations are functions of gel concentration. The following linear approximations are used in this study:

$$
\begin{array}{ll}
k_{r w}^{0}\left(S_{\mathrm{g}}\right)=k_{r w}^{f}+\left(k_{r w}^{\mathrm{g}}-k_{r w}^{f}\right) S_{\mathrm{g}} & k_{r o}^{0}\left(S_{\mathrm{g}}\right)=k_{r o}^{f}+\left(k_{r o}^{\mathrm{g}}-k_{r o}^{f}\right) S_{\mathrm{g}} \\
L_{w}\left(S_{\mathrm{g}}\right)=L_{w}^{f}+\left(L_{w}^{\mathrm{g}}-L_{w}^{f}\right) S_{\mathrm{g}} & L_{o}\left(S_{\mathrm{g}}\right)=L_{o}^{f}+\left(L_{o}^{\mathrm{g}}-L_{o}^{f}\right) S_{\mathrm{g}} \\
E_{w}\left(S_{\mathrm{g}}\right)=E_{w}^{f}+\left(E_{w}^{\mathrm{g}}-E_{w}^{f}\right) S_{\mathrm{g}} & E_{o}\left(S_{\mathrm{g}}\right)=E_{o}^{f}+\left(E_{o}^{\mathrm{g}}-E_{o}^{f}\right) S_{\mathrm{g}} \\
T_{w}\left(S_{\mathrm{g}}\right)=T_{w}^{f}+\left(T_{w}^{\mathrm{g}}-T_{w}^{f}\right) S_{\mathrm{g}} & T_{o}\left(S_{\mathrm{g}}\right)=T_{o}^{f}+\left(T_{o}^{\mathrm{g}}-T_{o}^{f}\right) S_{\mathrm{g}} \\
S_{w i}\left(S_{\mathrm{g}}\right)=S_{w i}^{f}+\left(S_{w i}^{\mathrm{g}}-S_{w i}^{f}\right) S_{\mathrm{g}} & S_{o r}\left(S_{\mathrm{g}}\right)=S_{o r}^{f}+\left(S_{o r}^{\mathrm{g}}-S_{o r}^{f}\right) S_{\mathrm{g}}
\end{array}
$$


Relative permeability curves were taken from Ref. [15] (Table 2).

Table 2. End point results in Vosges sandstone

\begin{tabular}{|c|c|c|c|c|c|}
\hline & & $\mathrm{S}_{\mathrm{wi}}$ & $\mathrm{k}_{\mathrm{ro}}$ & $\mathrm{S}_{\mathrm{or}}$ & $\mathrm{k}_{\mathrm{rw}}$ \\
\hline \multirow{2}{*}{ Water wet } & Before polymer & 0.33 & 0.89 & 0.34 & 0.062 \\
\cline { 2 - 6 } & After polymer & 0.49 & 0.55 & 0.33 & 0.0028 \\
\hline \multirow{2}{*}{ Oil wet } & Before polymer & 0.32 & 1.0 & 0.54 & 0.47 \\
\cline { 2 - 6 } & After polymer & 0.49 & 0.42 & 0.17 & 0.11 \\
\hline
\end{tabular}

Figs. 3-A and 3-B plot modification of relative permeability before and after polymer adsorption in water-wet sandstone taken from experiments, and approximations of the experimental data used in this model. They are more suitable for matricial than for fractured reservoirs [13].
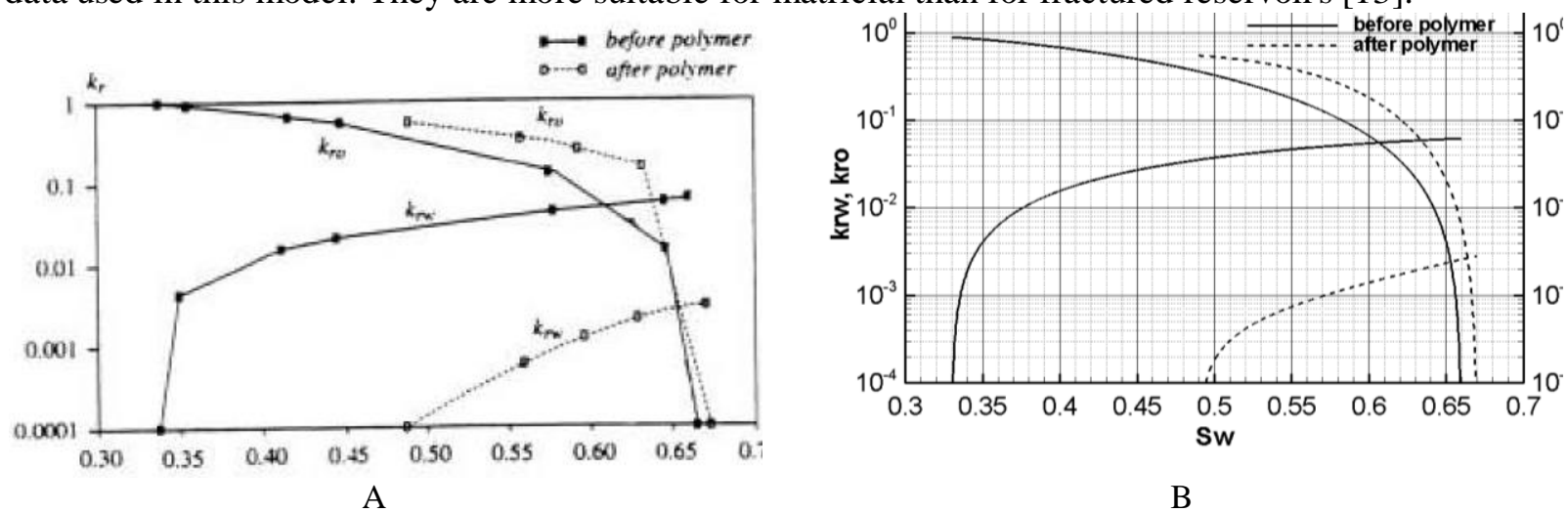

Figure 3. Modification of relative permeabilities before and after polymer adsorption in waterwet sandstone: from experiments (A), and approximation of the experimental data (B)

Another effectis the increase in capillary pressure after polymer adsorption (Fig. 4) [15]. New formula for approximation of Leverett $\mathrm{J}$-function is proposed in this work:

$$
J\left(S, S_{\mathrm{g}}\right)=\frac{J_{\max }\left(S_{\mathrm{g}}\right) \cdot(1-S)^{L\left(S_{\mathrm{g}}\right)}+J_{\min }\left(S_{\mathrm{g}}\right) \cdot E\left(S_{\mathrm{g}}\right) S^{T\left(S_{\mathrm{g}}\right)}}{(1-S)^{L\left(S_{\mathrm{g}}\right)}+E\left(S_{\mathrm{g}}\right) \cdot S^{T\left(S_{\mathrm{g}}\right)}}
$$

The following linear approximations are used in this study:

$$
\begin{gathered}
J_{\text {max }}\left(S_{\mathrm{g}}\right)=J_{\text {max }}^{f}+\left(J_{\text {max }}^{\mathrm{g}}-J_{\text {max }}^{f}\right) \cdot S_{\mathrm{g}} \\
J_{\text {min }}\left(S_{\mathrm{g}}\right)=J_{\text {min }}^{f}+\left(J_{\text {min }}^{\mathrm{g}}-J_{\text {min }}^{f}\right) \cdot S_{\mathrm{g}}
\end{gathered}
$$

$$
\begin{aligned}
& L\left(S_{\mathrm{g}}\right)=L^{f}+\left(L^{\mathrm{g}}-L^{f}\right) \cdot S_{\mathrm{g}} \\
& E\left(S_{\mathrm{g}}\right)=E^{f}+\left(E^{\mathrm{g}}-E^{f}\right) \cdot S_{\mathrm{g}} \\
& T\left(S_{\mathrm{g}}\right)=T^{f}+\left(T^{\mathrm{g}}-T^{f}\right) \cdot S_{\mathrm{g}}
\end{aligned}
$$

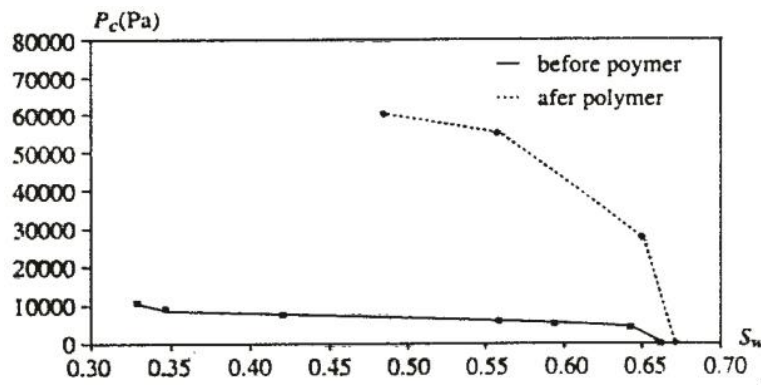

A

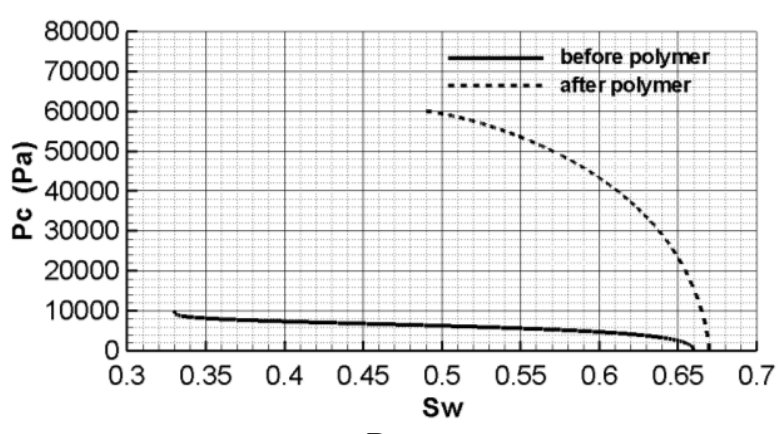

B

Figure 4. Capillary pressure as a function of water saturation before and after polymer adsorption in water-wet core from experiments (A), and its approximation used in model (B) 
The new formula for approximation of Leverett J-function is based on the idea of LET correlation, but it is generalized for case if it has negative value also. The new correlation takes into account gel transition zone hence it is a really powerful and universal for describing proper shape of the Leverett J-function. It is able to quite precisely approximate any monotonically decreasing smooth function by selection constants, and also unlike some formulas its derivative is not equal to infinity at zero. The new formulas approximate curves with sharp gradient as in Fig. 5.

Fig. 6 shows that numerical calculation of Leverett J-function derivative is not reliable as the function has high gradients usually. Analytical derivative of the proposed Leverett J-function is recommended for numerical implementation. The analytical derivative makes it possible to avoid the neglecting of certain values of the J-function numerical derivative at high gradient points. Using the analytical derivative gives an opportunity to save computational resources required for high accuracy methods for numerical computation of the derivative.

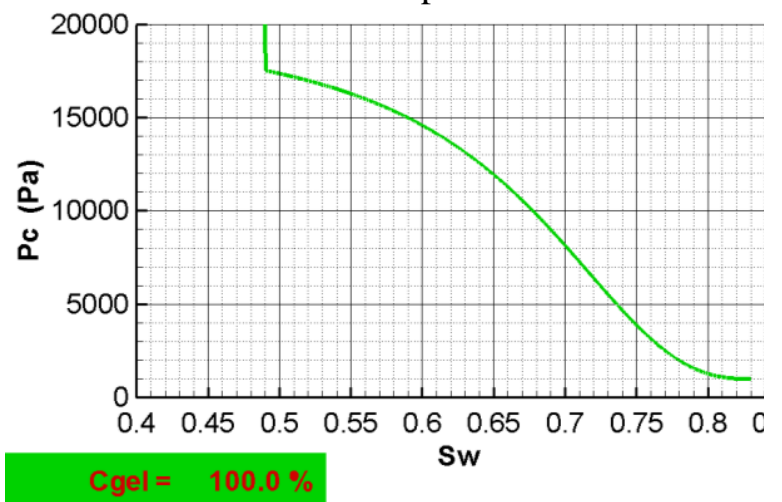

Figure 5. Capillary pressure in the gelsaturated zone

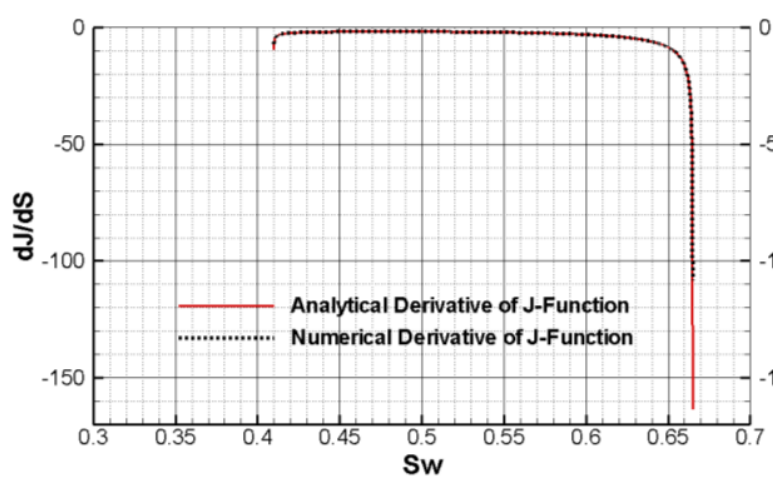

Figure 6. Derivative of Leverett J-function at $C_{\text {gel }}=\mathbf{5 0} \%$

\subsection{Posttreatment production forecasts}

Posttreatment production processes are described by the same mathematical model as used in the simulation of polymer injection. Fig. 7 illustrates the post-treatment water coning. Fig. 8 shows water cut for vertical well with and without gel treatment.

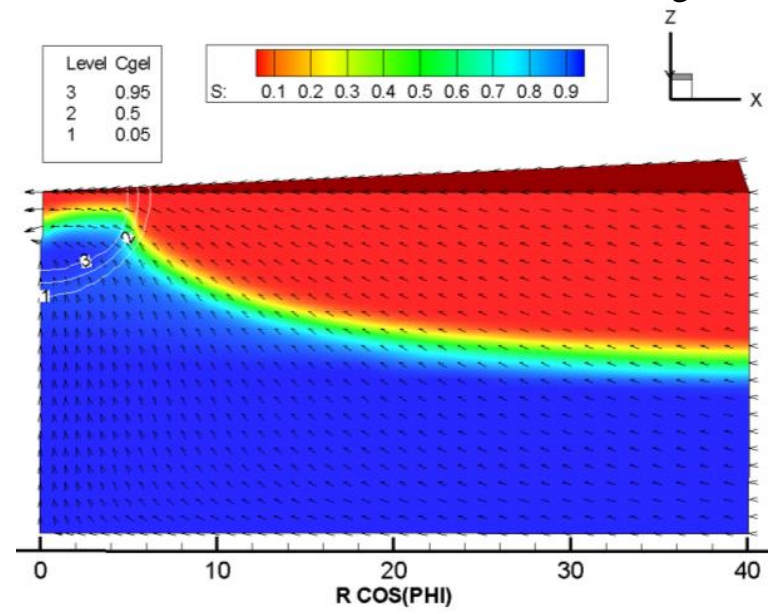

Figure 7. Water coning after gel treatment

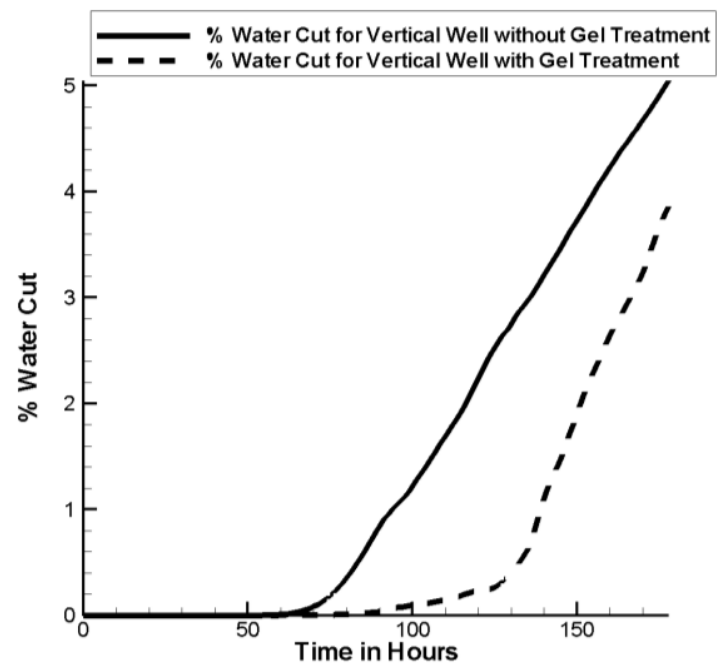

Figure 8. Water cut for vertical well with and without gel treatment 


\section{Numerical analysis of the effect of horizontal impermeable barrier and DWS technology on water coning performance}

Water coning control using horizontal impermeable barrier and downhole water sink technology is described by the same mathematical model as in 1.1 section, which results from incompressible two-phase flow equations formulated in terms of normalized saturation and global pressure.

\subsection{Three-dimensional numerical modeling of thermal two-phase flow in porous media}

Figure 1 illustrates the geometrical domain, boundaries and interfaces of the model which are used to apply initial and boundary conditions to fit the physics of the oil recovery process. Boundary conditions for pressure and saturation are derived from the following clear general statements:

$r=r_{w}, \quad 0<\varphi<2 \pi, H-H_{P} \leq z<H: \quad$ Thermal initial and boundary conditions:

$v_{r}=q, \quad q=\frac{Q}{2 \pi r_{w} H_{P}} ; \quad \frac{\partial\left(v_{w r} \cdot r\right)}{\partial r}=0$,

$r=0, \quad\left\{\begin{array}{c}0<\varphi<\pi, \quad 0<z<H-H_{P}: \\ \left.v_{r}\right|_{r+0, \varphi}=-\left.v_{r}\right|_{r+0, \varphi+\pi} \\ \left.v_{w r}\right|_{r+0, \varphi}=-\left.v_{w r}\right|_{r+0, \varphi+\pi} \\ \pi \leq \varphi<2 \pi, \quad 0<z<H-H_{P} \\ \left.v_{r}\right|_{r+0, \varphi}=-\left.v_{r}\right|_{r+0, \varphi-\pi} \\ \left.v_{w r}\right|_{r+0, \varphi}=-\left.v_{w r}\right|_{r+0, \varphi-\pi}\end{array}\right.$

$r=R, 0<\varphi<2 \pi, 0<z<H$ :

$\frac{\partial\left(v_{r} \cdot r\right)}{\partial r}=0, \quad \frac{\partial\left(v_{w r} \cdot r\right)}{\partial r}=0$,

$0<r<R, \quad 0<\varphi<2 \pi, \quad z=0$ :

$v_{z}(r, \varphi, z)=0, \quad v_{w z}(r, \varphi, z)=0$,

$0<r<R, \quad 0<\varphi<2 \pi, \quad z=H$ :

$v_{z}(r, \varphi, z)=0, \quad v_{w z}(r, \varphi, z)=0$,

$0<r<R, \quad 0<z<H$ :

$\left.v_{\varphi}\right|_{\varphi=0}=\left.v_{\varphi}\right|_{\varphi=2 \pi^{\prime}} ;\left.\quad v_{w \varphi}\right|_{\varphi=0}=\left.v_{w \varphi}\right|_{\varphi=2 \pi}$. $t=0$ :

$r_{0} \leq r \leq R, \quad\left(r_{0}=0\right.$ or $\left.r_{0}=r_{w}\right)$,

$0 \leq \varphi \leq 2 \pi, \quad 0 \leq z<H_{w}: \quad \theta=\theta_{w}$,

$r_{0} \leq r \leq R, \quad\left(r_{0}=0\right.$ or $\left.r_{0}=r_{w}\right)$,

$0 \leq \varphi \leq 2 \pi, H_{w} \leq z \leq H: \quad \theta=\theta_{o}$,

$t>0$ :

$r=0, \quad \frac{\pi}{2} \pm \frac{\pi}{2}<\varphi \leq \frac{3 \pi}{2} \pm \frac{\pi}{2}$,

$0<z<H-H_{P}:\left.\frac{\partial \theta}{\partial r}\right|_{r+0, \varphi}=-\left.\frac{\partial \theta}{\partial r}\right|_{r+0, \varphi \mp \pi} ;$

$r=r_{w}, \quad 0<\varphi<2 \pi$,

$H-H_{P} \leq z<H: \frac{\partial \theta}{\partial r}=0$,

$r=R, \quad 0<\varphi<2 \pi, \quad 0<z<H: \frac{\partial \theta}{\partial r}=0$,

$0<r<R, \quad 0<\varphi<2 \pi, \quad z=0: \frac{\partial \theta}{\partial z}=0$,

$0<r<R, \quad 0<\varphi<2 \pi, \quad z=H: \frac{\partial \theta}{\partial z}=0$,

$0<r<R, \quad 0<z<H:\left.\frac{\partial \theta}{\partial \varphi}\right|_{\varphi=0}=\left.\frac{\partial \theta}{\partial \varphi}\right|_{\varphi=2 \pi}$.

\subsection{Verification and validation of simulation model}

Qualitative verification of the developed simulator was done by comparing the numerical results with experimental data (case studies) [7]. Observed was the effects of the impermeable gel barrier and well completions on water coning in four different reservoir settings. The first was a case of conventional completion and was studied as a base case. In the second case was set dual completion with water drainage. The third scenario was an impermeable barrier injected around the well bore. In the fourth case was considered complex effect of dual completion with water drainage and impermeable barrier. Table 3 shows the cases analyzed in this study.

Table 3. Description of the cases analyzed in this study

\begin{tabular}{|c|c|c|c|c|}
\hline Case No. & 1 & 2 & 3 & 4 \\
\hline Description & $\begin{array}{c}\text { W/o barrier and w/o } \\
\text { drainage }\end{array}$ & $\begin{array}{c}\text { W/o barrier and with } \\
\text { drainage }\end{array}$ & $\begin{array}{c}\text { With barrier and w/o } \\
\text { drainage }\end{array}$ & $\begin{array}{c}\text { With barrier and with } \\
\text { drainage }\end{array}$ \\
\hline
\end{tabular}


A numerical simulation was carried out with a production rate of $1000 \mathrm{bbl} / \mathrm{d}$ from the oil completion and water was produced from the lower completion at a rate of $3000 \mathrm{bbl} / \mathrm{d}$. In this study lower completion in the water zone produces three times more fluid than upper completion because it was revealed that dual completion can stop water coning but for doing that the water production rate from the drainage has to be much higher than the oil production rate [6]. Both pumps, i.e. oil and water, are started simultaneously. For this study the field prototype has the properties as shown in Table 4 [16].

Table 4. Reservoir geometry, rock and fluid properties considered for the all 4 cases

\begin{tabular}{|c|c|c|c|c|c|}
\hline Property & $\begin{array}{l}\text { Denotation } \\
\text { (Unit) }\end{array}$ & Value & Property & $\begin{array}{l}\text { Denotation } \\
\text { (Unit) }\end{array}$ & Value \\
\hline $\begin{array}{l}\text { Initial Water Zone } \\
\text { Thickness }\end{array}$ & $H_{w}(\mathrm{~m})$ & 10 & $\begin{array}{c}\text { Total Production Rate in Oil } \\
\text { Zone }\end{array}$ & $Q_{1}(\mathrm{bbl} / \mathrm{d})$ & 1000 \\
\hline $\begin{array}{l}\text { Initial Oil Zone } \\
\text { Thickness }\end{array}$ & $H_{o}(\mathrm{~m})$ & 10 & $\begin{array}{l}\text { Water production rate in water } \\
\text { zone }\end{array}$ & $Q_{2}(\mathrm{bbl} / \mathrm{d})$ & 3000 \\
\hline $\begin{array}{l}\text { Well Perforation } \\
\text { Thickness }\end{array}$ & $H_{p}(\mathrm{~m})$ & 3 & Water Density & $\rho_{w}\left(\mathrm{~kg} / \mathrm{m}^{3}\right)$ & 1000 \\
\hline Water Viscosity & $\mu_{w}(c p)$ & 0.5 & Oil Density & $\rho_{o}\left(\mathrm{~kg} / \mathrm{m}^{3}\right)$ & 730 \\
\hline Oil Viscosity at $\theta_{\min }$ & $\mu_{\text {omax }}(c p)$ & 5 & Thermal Conductivity of Water & $\lambda_{w}(W /(\mathrm{m} \cdot K))$ & 0.644 \\
\hline Oil Viscosity at $\theta_{\max }$ & $\mu_{o \min }(c p)$ & 1 & Thermal Conductivity of Oil & $\lambda_{o}(W /(\mathrm{m} \cdot K))$ & 0.08 \\
\hline $\begin{array}{l}\text { Irreducible Water } \\
\text { Saturation }\end{array}$ & $S_{w i}$ (fraction) & 0.2 & Thermal Conductivity of Core & $\lambda_{c}(W /(\mathrm{m} \cdot K))$ & 2.4 \\
\hline Residual Oil Saturation & $S_{o r}$ (fraction) & 0.2 & Initial Water Zone Temperature & $\theta_{\max }(K)$ & 350 \\
\hline & & & Initial Oil Zone Temperature & $\theta_{\min }(K)$ & 330 \\
\hline
\end{tabular}

\subsection{Results and discussion}

In this research the main focus was on excessive water due to coning. One of the methods that have been tried by the industry to control water coning is injection of gels and polymers around the well bore. These gels create an artificial impermeable barrier around the well, which does not allow flow of water across it. In order to study the effect of stratification on DWS, a numerical experiment was carried out with a zero permeability barrier. To demonstrate the radial effect, barrier with various radius was used. The results of 3D simulation is shown in Figs. 9 and 10. Fig. 9 shows that breakthrough time is directly proportional to the radius of gel barrier.

The Figs. 11.1-11.4 show the effects of impermeable barrier and DWS technology for the different reservoir settings. The figures show $0^{0}-180^{\circ}$ cross-section of the reservoir. Cone height vs. time was studied and it was observed that cone development in single completion is much faster than in DWS completion. Temperature field distributions at $\mathrm{t}=16$ days are presented in Fig. 11.

Time related development of dynamic shapes of the OWC and the water-cut development with time were compared with base case cone development (Figs. 12.1 and 12.3). It was revealed that for homogeneous reservoirs in presence of impermeable barrier between conventional well and bottom water, water coning develops on point at OWC which is in the shortest open distance from well completion. It is concluded that impermeable barrier is as efficient as it close to well completion. 
Water cut values from DWS simulation were compared with conventional-coning simulation as shown in Figs. 12.1 and 12.2. Results show that dual completion decreases water-cut in oil production by draining water from the bottom completion and producing oil from the top completion. It has been revealed that DWS is more efficient when it is placed as close as possible to OWS.

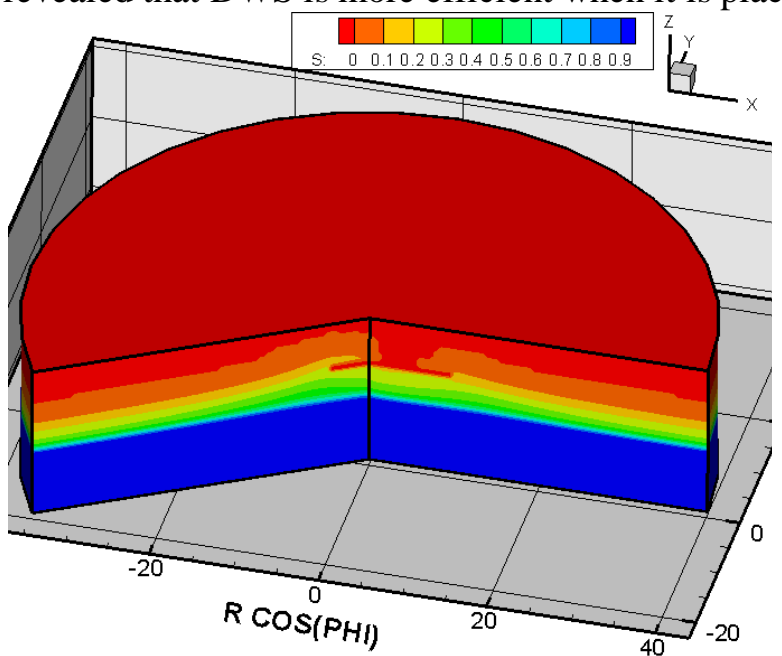

Figure 9. Water saturation distribution at $\mathbf{t}=\mathbf{8 5}$ hours

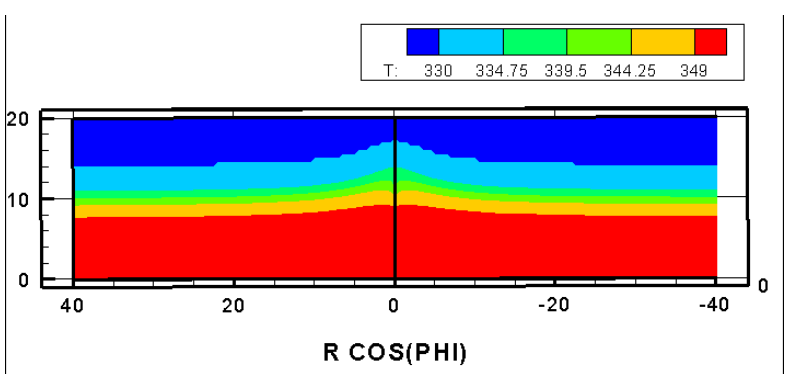

Case 1

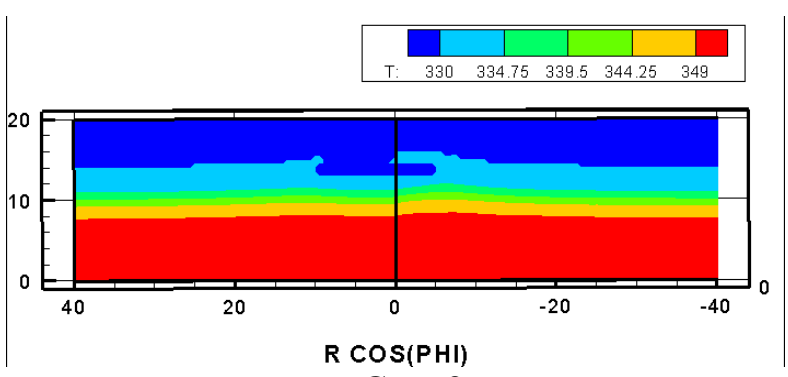

Case 3

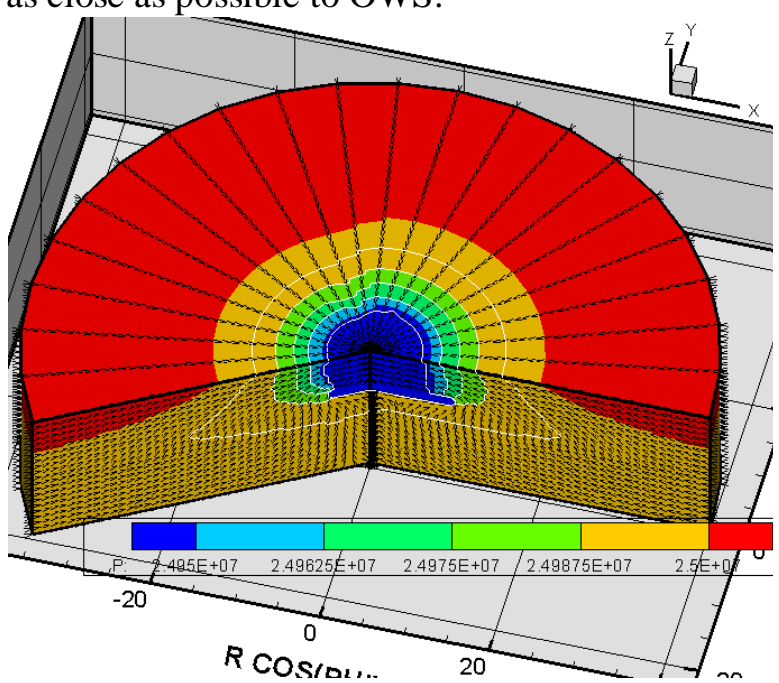

Figure 10. Pressure and velocity distribution at $\mathbf{t}=90$ hours

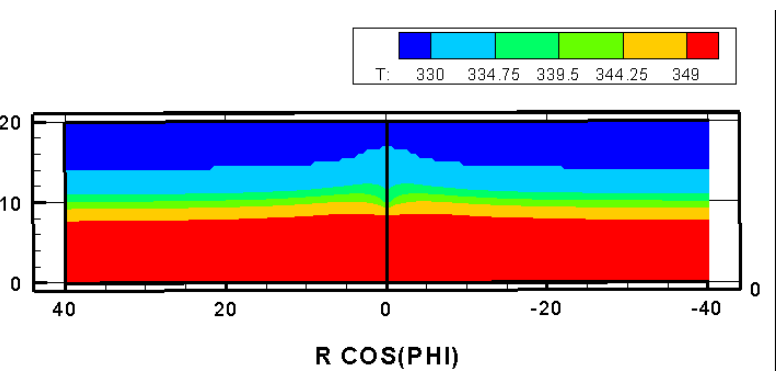

Case 2

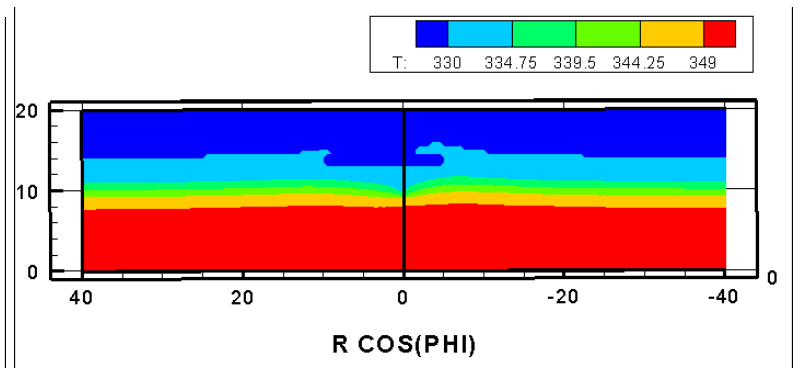

Case 4

Figure 11. Temperature field distribution at $t=16$ days for Cases $1,2,3,4$, respectively

Also numerical experiments were carried out with an impermeable barrier above the OWC. Watercut development with time was compared with the values obtained with the water sink. Time related development of dynamic shapes of the OWC was compared with single completion case.

The results from the model suggest that although placement of impermeable barrier delays the breakthrough of water, it does not stop water-coning process. It is shown that in case of high oil production rate, the water simply goes around the barrier's top and breaks to the well's completion as has been observed in the numerical experiments. However, the water-cut development in the case of an impermeable barrier shows a delayed breakthrough of water, which can be beneficial in producing 
water free oil for a longer period of time. One thing that needs to be pointed here is that the length of impermeable barrier in experimental model was $12.5-25 \%$ of the drainage radius. Such a long and thin man made impermeable barrier is not practically feasible in an actual reservoir setting.

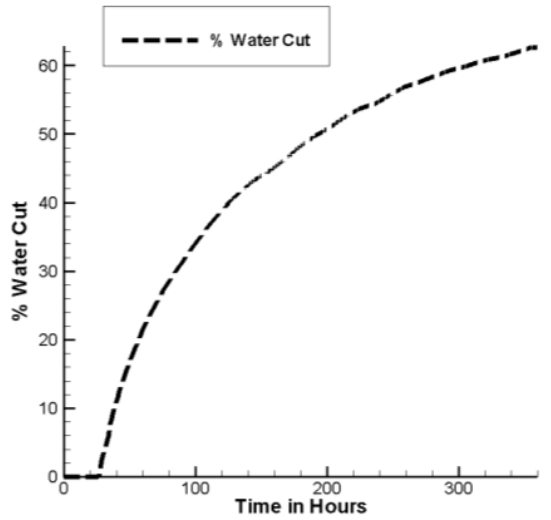

Figure 12.1. Water cut for Case 1

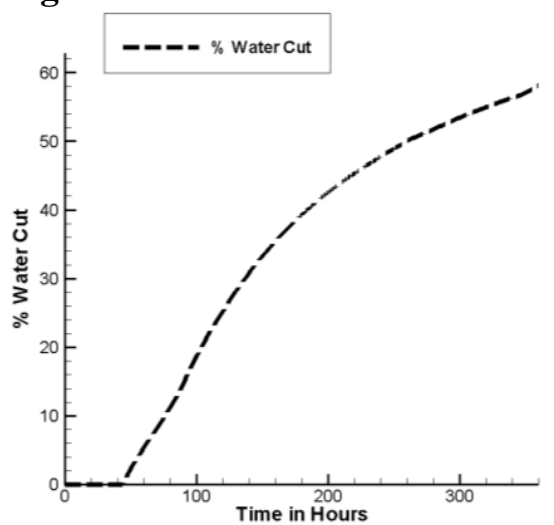

Figure 12.3. Water cut for Case 3

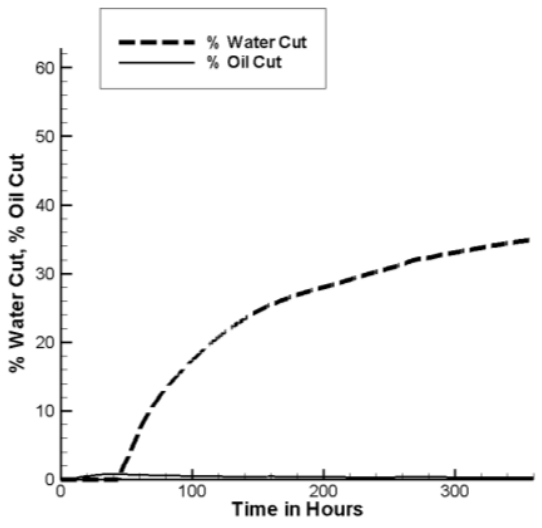

Figure 12.2. Water cut for Case 2

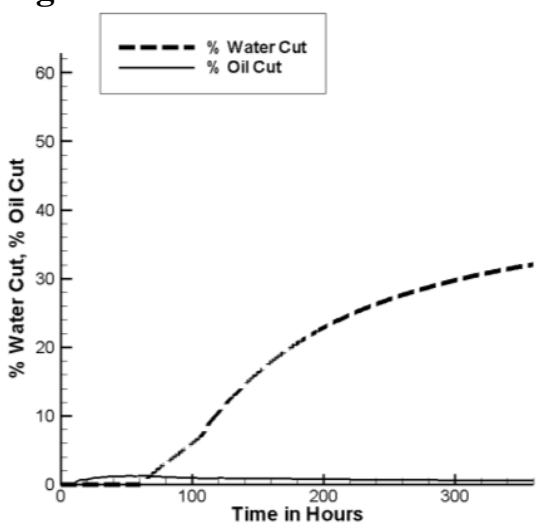

Figure 12.4. Water cut for Case 4

\section{Conclusions}

Thermal mathematical model based on the MLT model of the two-phase immiscible fluids' flow through a porous medium has been developed, which takes into consideration of the most important displacement mechanisms and physical and rheological phenomena involved in oil recovery process. A generalized version of the LET correlation for relative permeability approximation which takes into account gel - reservoir fluid transition zone is proposed. New formula for approximation of Leverett $\mathrm{J}$-function is also proposed. Based on the developed mathematical model, the numerical model and simulation tool for analyzing near-well flow has been developed. The simulation tool has been applied for simulating gel treatment for in-situ permeability modification, posttreatment production forecasts, production tests with/without artificial impermeable barrier, the effect of DWS technology on water coning performance, and some combinations of above methods. Mechanistic study of gel injection process shows that impact of gel / reservoir fluid viscosity ratio play large role in gel distribution in a homogeneous reservoir. For a given volume of gelant injected, the gelant penetration zone and gelant - reservoir fluid transition zone are greater for a low-viscosity than for a viscous gelant (other factors being equal). The numerical study of posttreatment production with specific input data was provided. This study shows that the breakthrough time is directly proportional to the radius of gel barrier. The study also shows that for homogeneous reservoirs in presence of impermeable barrier between conventional well and bottom water, water coning develops on point at 
OWC which is in the shortest open distance from well completion. It has been revealed that impermeable barrier is as efficient as it close to well completion, and DWS is more efficient when it is placed as close as possible to OWC.

\section{References}

[1] Hernandez, J. C. Oil Bypassing by Water Invasion to Wells: Mechanisms and Remediation. A Dissertation for the degree of Doctor of Philosophy in the Department of Petroleum Engineering. Louisiana State University, 2007.

[2] Motiff, Ph. D. Long-Term Production Results of Polymer Treatments in Producing Wells in Western Kansas. JPT P. 356 (04.1993).

[3] Schneider, F. N., Owens, W. W. Steady-State Measurements of Relative Permeability for Polymer, Oil Systems. SPEJ P. 79 (02.1982).

[4] Liang, J. T., Sun, H., Seright, R. S. Why Do Gels Reduce Water Permeability More Than Oil Permeability? SPERE, P. 282. (11.1995).

[5] Wojtanowicz, A. K., Shirman, E. I., Kurban, H. Downhole Water Sink (DWS) Completion Enhance Oil Recovery in Reservoirs with Water Coning Problem. SPE 56721, presented at the Annual Technical Conference and Exhibition, Houston, TX, (Oct. 3-6, 1999).

[6] Shirman, E. I., Wojtanowicz, A. K. More Oil Using Downhole Water Sink Technology: A Feasibility Study. SPE Prod. \& Facilities 15(4), (Nov. 2000).

[7] Siddiqi, S. S., Wojtanowicz, A. K. A Study of Water Coning Control in Oil Wells by Injected or Natural Flow Barriers Using Scaled Physical Model and Numerical Simulator. SPE 77415, 2002.

[8] Chen, T., Wan, W. Modified Polymer Gels for Creating a Horizontal Barrier to Block Off Water Coning. Presented at the 47th Annual Technical Meeting of the Petroleum Society, Calgary, Alberta, Canada, (June 10-12, 1996).

[9] Strickland, R. F. Artificial Barriers may Control Water Coning-1. O\&GJ, 61-64 (Oct.7, 1974).

[10]Zhumagulov, B. T. , Monakhov V. N. The Fluid Dynamics of Oil Production, Translated \& ed. by AgipK CO, Milan: Interservice, P. 307, 2003.

[11]Barenblatt, G. I., Patzek, T. W., Silin, D. B. The Mathematical Model of Non-Equilibrium Effects in Water-Oil Displacement. SPE 75169 presented at SPE/DOE Improved Oil Recovery Symposium, Tulsa, Oklahoma, (April 13-17, 2002).

[12]Бочаров, О. Б., Телегин, И. Г. Численное исследование гидрофизических процессов при сопряжении различных неизотермических моделей фильтрации двухфазной жидкости. Теплофизика и аэромеханика Т. 12 №4, 657-667 (2005).

[13]Zaitoun, A., Kohler, N., Bossie-Codreanu, D., Denys, K. Water Shutoff by Relative Permeability Modifiers: Lessons from Several Field Applications. SPE 56740 presented at the 1999 SPE Annual Technical Conference and Exhibition held in Houston, Texas, (October 3-6, 1999).

[14]Lomeland, F., Ebeltoft, E., Hammervold, T. W. A New Versatile Relative Permeability Correlation. Reviewed Proceedings of 2005 International Symposium of SCA, Abu Dhabi, United Arab Emirates, SCA 2005-32 (Nov. 2, 2005).

[15]Zaitoun, A., Bertin, H., Lasseux, D. Two-Phase Flow Property Modifications by Polymer Adsorption. SPE 39631 presented at the 1998 SPE/DOE IOR Symposium, Tulsa, OK.

[16]Bekbauov, B. E., Kaltayev, A., Nagy, S. Three-Dimensional Thermal Petroleum Filtration Study of Water Coning. Archives of Mining Sciences, Cracow, Poland 55 No 1, 201-215 (2010). 